\title{
Docking, Interaction Fingerprint, and Three-Dimensional Quantitative Structure-Activity Relationship (3D-QSAR) of Sigma1 Receptor Ligands, Analogs of the Neuroprotective Agent RC-33
}

\author{
José Luis Velázquez-Libera ${ }^{1}$, Giacomo Rossino ${ }^{2}$, Carlos Navarro-Retamal ${ }^{1}$, \\ Simona Collina ${ }^{2}$ and Julio Caballero ${ }^{1 *}$ \\ ${ }^{1}$ Centro de Bioinformática y Simulación Molecular, Facultad de Ingeniería, Universidad de Talca, Talca, Chile, \\ ${ }^{2}$ Pharmaceutical and Medicinal Chemistry Section, Drug Sciences Department, Università di Pavia, Pavia, Italy
}

OPEN ACCESS

Edited by:

Teodorico Castro Ramalho, Universidade Federal de Lavras, Brazil

Reviewed by:

Andrei I. Khlebnikov, Tomsk Polytechnic University, Russia Marco Tutone,

University of Palermo, Italy

*Correspondence: Julio Caballero jcaballero@utalca.cl

Specialty section:

This article was submitted to Medicinal and Pharmaceutical

Chemistry,

a section of the journa

Frontiers in Chemistry

Received: 12 April 2019 Accepted: 27 June 2019

Published: 11 July 2019

Citation:

Velázquez-Libera JL, Rossino G, Navarro-Retamal C, Collina S and Caballero J (2019) Docking Interaction Fingerprint, and Three-Dimensional Quantitative Structure-Activity Relationship (3D-QSAR) of Sigma1 Receptor

Ligands, Analogs of the Neuroprotective Agent RC-33.

Front. Chem. 7:496. doi: 10.3389/fchem.2019.00496
The human Sigma1 receptor (S1R), which has been identified as a target with an important role in neuropsychological disorders, was first crystallized 3 years ago. Since S1R structure has no relation with another previous crystallized structures, the presence of the new crystal is an important hallmark for the design of agonists and antagonists against this important target. Some years ago, our group identified RC-33, a potent and selective S1R agonist, endowed with neuroprotective properties. In this work, drawing on new structural information, we studied the interactions of RC-33 and its analogs with the S1R binding site by using computational methods such as docking, interaction fingerprints, and receptor-guided alignment three dimensional quantitative structure-activity relationship (3D-QSAR). We found that RC-33 and its analogs adopted similar orientations within S1R binding site, with high similitude with orientations of the crystallized ligands; such information was used for identifying the residues involved in chemical interactions with ligands. Furthermore, the structure-activity relationship of the studied ligands was adequately described considering classical QSAR tests. All relevant aspects of the interactions between the studied compounds and S1R were covered here, through descriptions of orientations, binding interactions, and features that influence differential affinities. In this sense, the present results could be useful in the future design of novel S1R modulators.

Keywords: sigma1 receptor ligands, RC-33, arylalkylamine derivates, docking, quantitative structure-activity relationships, interaction fingerprints

\section{INTRODUCTION}

The Sigma receptors (SR) have attracted the interest of the scientific community thoroughly in the last decades owing to their potential role in cell survival and function modulation (Walker et al., 1990; Chu and Ruoho, 2016). They were originally misclassified as a subtype of opioid receptors (Martin et al., 1976), but they were later classified as unique class of intracellular proteins, 
distinct from other receptors such as GPCRs (G protein-coupled receptors). Sigma receptors (SRs), comprise two subtypes $\sigma_{1}$ and $\sigma_{2}$ receptors (S1R and $\mathrm{S} 2 \mathrm{R}$, respectively) associated with agingand mitochondria-associated disorders (Tesei et al., 2018). Both subtypes are highly expressed in the central nervous system, but they are derived from completely different genes. S1R was cloned in 1996 (Hanner et al., 1996) and was crystallized for the first time 3 years ago, in 2016 (Schmidt et al., 2016), whereas S2R was cloned only very recently, in 2017, by Alon et al. (2017).

$\mathrm{S} 1 \mathrm{R}$ is an intracellular modulator between the endoplasmic reticulum and the mitochondria, the cell nuclei, the membrane, and it also modulates intracellular signaling. It plays a key role in neuropsychological disorders such as depression, enhances the glutamatergic neurotransmission (DeCoster et al., 1995; Meyer et al., 2002), and modulates second messenger systems, such as the phospholipase C/protein kinase C/inositol 1,4,5trisphosphate system (Morin-Surun et al., 1999). Multiple biological roles of S1R have been identified, which made this protein a relevant target for the future treatment of epilepsy, schizophrenia, sclerosis, Alzheimer, and Parkinson's diseases, cancer, etc. (Mishina et al., 2005; Hashimoto, 2009; Furuse and Hashimoto, 2010; Mavlyutov et al., 2015; Vavers et al., 2017; Tesei et al., 2018). Moreover, S1R agonists enhanced neuroplasticity, and may be effective in amyotrophic lateral sclerosis (Peviani et al., 2014) and multiple sclerosis (Collina et al., 2017b).

Not less important, preclinical studies carried out on different models of memory impairment have revealed that S1R ligands could be promising drugs to treat cognitive dysfunctions (Hayashi and Su, 2004; Monnet and Maurice, 2006; Yagasaki et al., 2006; Collina et al., 2017a). Therefore, the identification of potent and selective S1R modulators is of great interest to develop novel therapeutic strategies focused mainly in the treatment of central nervous system disorders. The list of S1R ligands in the last years includes thioxanthene-derived compounds (Glennon et al., 2004), fenpropimorph-derived analogs (Hajipour et al., 2010), 2(3H)-benzothiazolones (Yous et al., 2005), cyclopropylmethylamines (Prezzavento et al., 2007), benzo[d]oxazol-2(3H)-one derivatives (Zampieri et al., 2009), etc. All these compounds were developed when the threedimensional (3D) structure of S1R was unknown. Despite this, the pharmacophoric features of S1R were identified and these compounds comply with the general accepted pharmacophoric pattern. It was demonstrated that at least one $\mathrm{N}$ positively charged atom is important for binding at sigma receptors and this atom must be flanked by two hydrophobic regions of different sizes (Ablordeppey et al., 2000; Glennon, 2005; Caballero et al., 2012).

In the last years, we designed and synthesized compounds that comply with the proposed pharmacophore model and evaluated them as S1R ligands (Collina et al., 2007; Urbano et al., 2007; Rossi et al., 2010, 2011), leading to the finding of compound RC-33 as a potent and selective S1R agonist (Rossi et al., 2013a; Marra et al., 2016). The structure-activity relationship (SAR) of the majority of these compounds was previously described by us by using 2D-QSAR methodologies (Quesada-Romero et al., 2015). With the recent report of the S1R 3D structure (Schmidt et al., 2016), structure-based molecular modeling methods could be used to investigate S1R ligands with a new glance. With this in mind, we propose in this work the analysis of the SAR of $\mathrm{RC}-33$ and its analogs (in total there were 80 compounds) by combining docking and a 3D-QSAR methodology. This is the first study focused on describing the SAR of S1R ligands by using structure-based molecular modeling methods, after the report of the crystallographic structure of this important biological target.

\section{MATERIALS AND METHODS \\ Dataset Preparation}

The studied compounds were extracted from references (Collina et al., 2007; Urbano et al., 2007; Rossi et al., 2010, 2011, 2015, 2017; Rui et al., 2016). This dataset yielded a total of 80 compounds with reported activities as Ki ranging from 0.00069 to $1 \mu \mathrm{M}$. Ki values were converted into logarithmic $\mathrm{pKi}$ values prior 3D-QSAR models' elaboration. The compound chemical structures and their $\mathrm{pKi}$ values are depicted in Table 1. The molecular structures were sketched using Maestro's molecular editor (Maestro 10.2.011, Schrödinger LLC). Thereafter, the 3D structures were obtained with the help of the LigPrep module (LigPrep, Maestro 10.2.011, Schrödinger LLC); ionization states were generated at pH $7.0 \pm 2.0$ using Epik (Shelley et al., 2007). For compounds containing two possible enantiomers which are reported in racemic form, the $R$ enantiomer was chosen for QSAR experiments because it was determined that both RC-33 enantiomers showed similar affinities for the S1R and they are almost equally effective as S1R agonists (Rossi et al., 2013b). However, both enantiomers were chosen for docking experiments to explore the interactions in the S1R binding site.

\section{Molecular Docking}

The ligand-receptor molecular docking experiments of RC33 analogs into the active site of S1R were performed by using the software Glide from the Schrödinger suite (Friesner et al., 2004). Glide is one of the most effective docking programs at this moment with many successful applications relating to rational design of novel drugs and investigation of protein-ligand interactions. Such applications encompass in silico search of novel drugs (Osguthorpe et al., 2012; Amaning et al., 2013), analysis of the SAR of congeneric series of compounds (Almerico et al., 2012; Quesada-Romero and Caballero, 2014; QuesadaRomero et al., 2014; Mena-Ulecia et al., 2015), evaluation of enzymatic reaction pathways (Wu et al., 2011; Batra et al., 2013), etc.

Protein coordinates were extracted from the crystal structure of S1R bound to the selective antagonist PD144418 (code 5HK1 in Protein Data Bank) (Schmidt et al., 2016). A grid box of $20 \times 20 \times 20 \AA$ was centered on the center of mass of the ligand in this crystal structure covering the binding site of S1R. Glide standard (SP) and extra-precision (XP) modes were employed with the same protocol and parameters that were used by us in previous works (Quesada-Romero and Caballero, 2014; Quesada-Romero et al., 2014; Mena-Ulecia et al., 2015). Glide SP was used to evaluate the capability of the Glide method to obtain poses that fit the known pharmacophore of S1R ligands, 
Velázquez-Libera et al.

Modeling of Sigma Receptor Ligands

TABLE 1 | Structures of RC-33 analogs as S1R ligands.

ID

Structure

Experimental

Predicted

References

$\mathrm{pKi}^{\mathrm{b}}$

$\mathrm{pKi}^{\mathrm{b}}$<smiles>C[C@H](CCN1CCCCC1)c1ccc(-c2ccccc2)cc1</smiles>

9.16

9.37

Ross et al., 2011

1 (RC-33)<smiles>CN(C)CC[C@](C)(O)c1ccc2ccccc2c1</smiles>

7.60

7.54

Collin et al., 2007<smiles>COc1ccc2cc(C(C)(C)O)ccc2c1</smiles>

7.41

7.49

Ross et al., 2010

4<smiles>CC(=CCN(C)C)c1ccc2ccccc2c1</smiles>

6.99

6.96

Collin et al., 2007

5<smiles>COc1ccc2cc(/C(C)=C/CN(C)C)ccc2c1</smiles>

7.70

7.62

Collin et al., 2007

62<smiles>C/C(=C\CN(C)C)c1ccc(-c2ccccc2)cc1</smiles>

7.67

7.44

Collin et al., 2007

7<smiles>C/C(=C\CN(C)C)c1ccccc1</smiles>

8.85

8.73

Ross et al., 2011

$8^{a}$<smiles>COc1ccc(/C(C)=C/CN(C)C)cc1</smiles>

6.00

6.79

Ross et al., 2011

9

6.09

6.23

Ross et al., 2011<smiles>COc1cccc(/C(C)=C/CN(C)C)c1</smiles>

6.00

6.14

Ross et al., 2011

(Continued)

Frontiers in Chemistry | www.frontiersin.org

3

July 2019 | Volume 7 | Article 496 
TABLE 1 | Continued

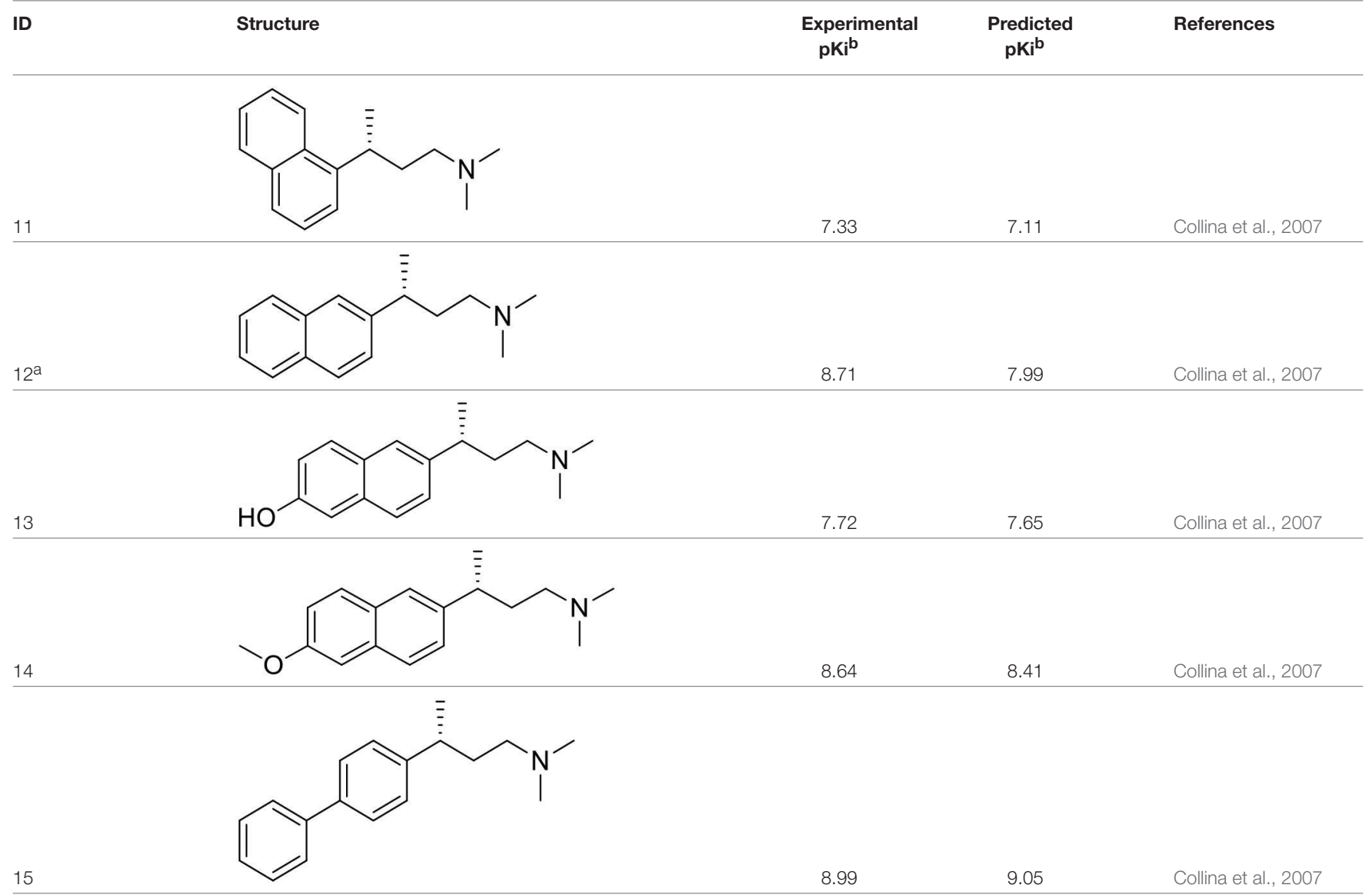

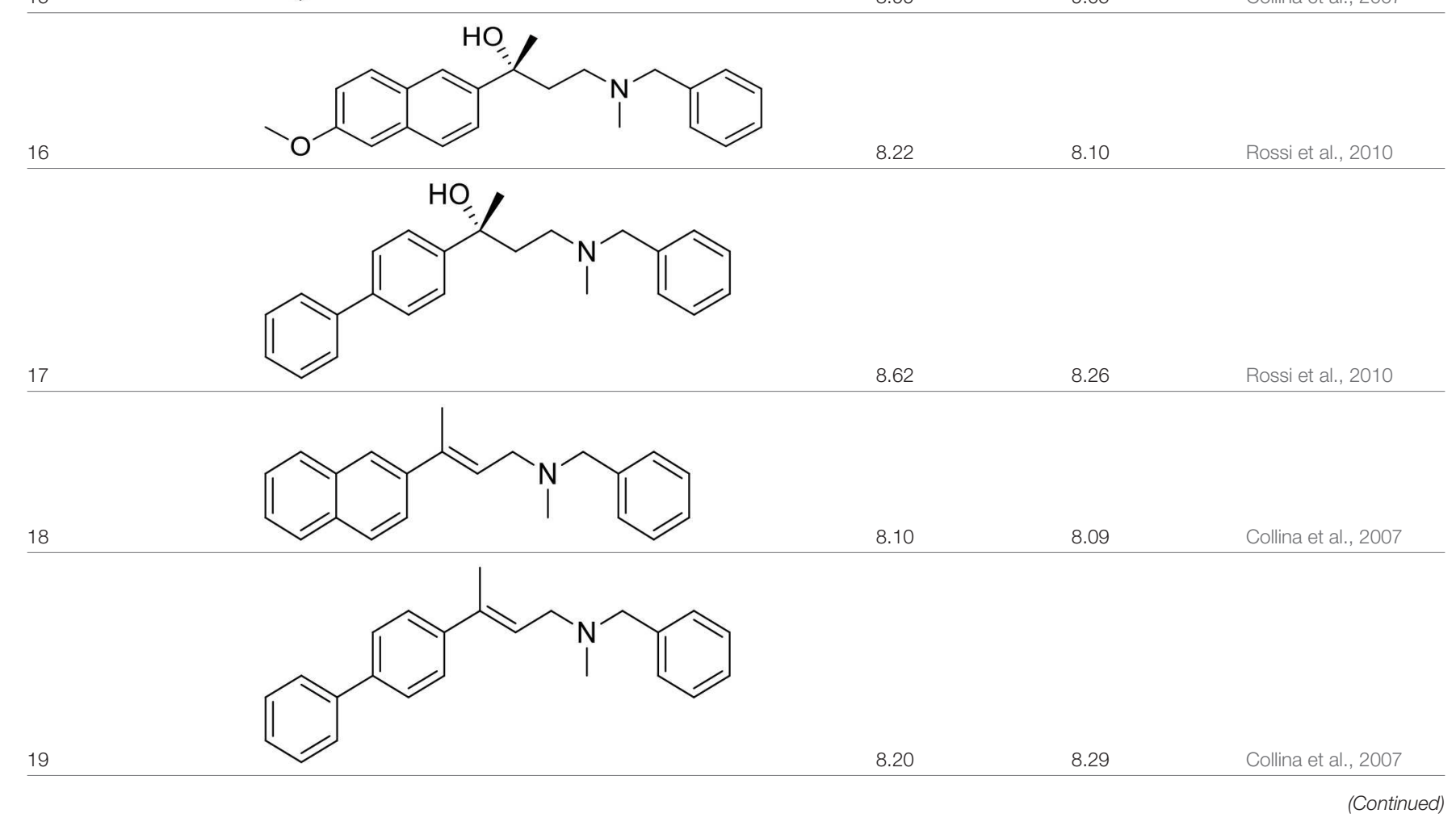


TABLE 1 | Continued

\begin{tabular}{|c|c|c|c|c|}
\hline ID & Structure & $\begin{array}{l}\text { Experimental } \\
\text { pKi }^{\mathbf{b}}\end{array}$ & $\begin{array}{l}\text { Predicted } \\
\text { pKi }^{\mathbf{b}}\end{array}$ & References \\
\hline 20 & & 7.86 & 8.22 & Rossi et al., 2010 \\
\hline 21 & & 7.04 & 7.06 & Collina et al., 2007 \\
\hline $23^{a}$ & & 8.27 & 8.96 & Collina et al., 2007 \\
\hline 26 & & 7.98 & 8.01 & Rossi et al., 2010 \\
\hline 27 & & 9.01 & 8.79 & Rossi et al., 2011 \\
\hline 28 & & 9.07 & 9.22 & Rossi et al., 2011 \\
\hline
\end{tabular}


TABLE 1 | Continued

ID

Rossie al, 2011

35<smiles>C/C(=C\CN1CCC(Cc2ccccc2)CC1)c1ccc(-c2ccccc2)cc1</smiles>

$36^{\mathrm{a}}$<smiles>C/C(=C\CN1CCC(Cc2ccccc2)CC1)c1ccccc1</smiles>

8.97

8.56

Rossi et al., 2011

$37^{\mathrm{a}}$<smiles>COc1ccc(/C(C)=C/CN2CCC(Cc3ccccc3)CC2)cc1</smiles><smiles>COc1cccc(/C(C)=C/CN2CCC(Cc3ccccc3)CC2)c1</smiles> 
TABLE 1 | Continued

\begin{tabular}{|c|c|c|c|c|}
\hline ID & Structure & $\begin{array}{l}\text { Experimental } \\
\mathbf{p K i}^{\mathbf{b}}\end{array}$ & $\begin{array}{l}\text { Predicted } \\
\text { pKi }^{\mathbf{b}}\end{array}$ & References \\
\hline 39 & & 8.02 & 8.04 & Rossi et al., 2011 \\
\hline 40 & & 7.94 & 7.83 & Rossi et al., 2011 \\
\hline 41 & & 6.00 & 6.38 & Rossi et al., 2011 \\
\hline 42 & & 6.00 & 5.98 & Rossi et al., 2011 \\
\hline $43^{a}$ & & 6.00 & 7.29 & Urbano et al., 2007 \\
\hline 44 & & 6.00 & 6.03 & Urbano et al., 2007 \\
\hline 45 & & 6.00 & 6.16 & Urbano et al., 2007 \\
\hline 46 & & 6.00 & 5.78 & Urbano et al., 2007 \\
\hline $47^{a}$ & & 6.00 & 6.36 & Urbano et al., 2007 \\
\hline
\end{tabular}


TABLE 1 | Continued

\begin{tabular}{|c|c|c|c|c|}
\hline ID & Structure & $\begin{array}{l}\text { Experimental } \\
\text { pKi }^{\mathbf{b}}\end{array}$ & $\begin{array}{l}\text { Predicted } \\
\text { pKi }^{\mathbf{b}}\end{array}$ & References \\
\hline 48 & & 6.00 & 5.89 & Urbano et al., 2007 \\
\hline 49 & & 6.00 & 5.75 & Urbano et al., 2007 \\
\hline 50 & & 7.41 & 7.52 & Rossi et al., 2015 \\
\hline 51 & & 8.33 & 8.37 & Rossi et al., 2015 \\
\hline
\end{tabular}

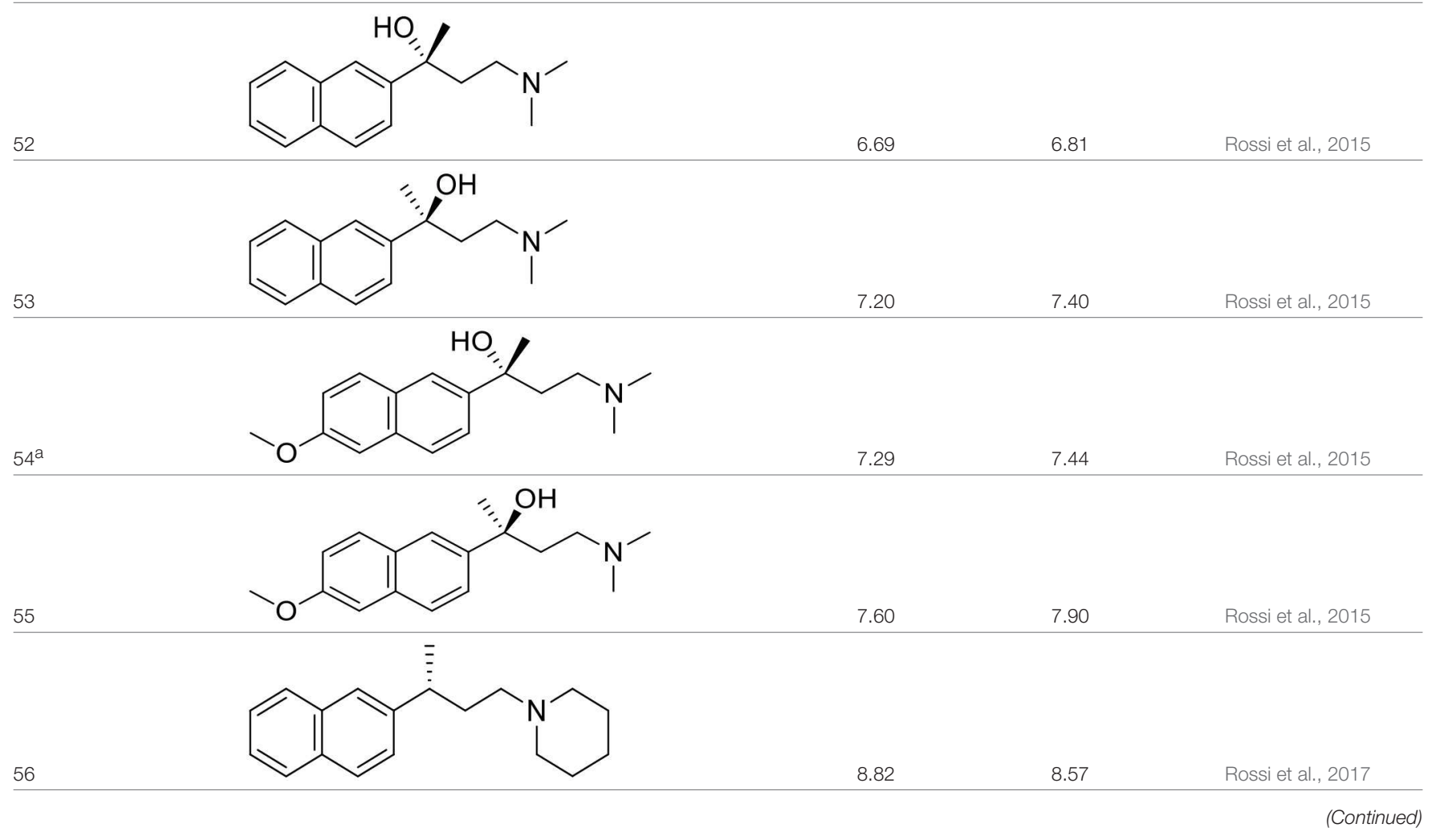


TABLE 1 | Continued

\begin{tabular}{|c|c|c|c|c|}
\hline ID & Structure & $\begin{array}{l}\text { Experimental } \\
\text { pKi }^{\mathbf{b}}\end{array}$ & $\begin{array}{l}\text { Predicted } \\
\text { pKi }^{\mathbf{b}}\end{array}$ & References \\
\hline 57 & & 8.22 & 8.29 & Rossi et al., 2017 \\
\hline 58 & & 8.16 & 8.14 & Rossi et al., 2017 \\
\hline 60 & & 6.94 & 6.91 & Rossi et al., 2017 \\
\hline 61 & & 7.70 & 7.68 & Rossi et al., 2017 \\
\hline 63 & & 7.12 & 7.20 & Rossi et al., 2017 \\
\hline 64 & & 6.62 & 6.75 & Rossi et al., 2017 \\
\hline $65^{a}$ & & 7.44 & 6.42 & Rossi et al., 2017 \\
\hline 66 & & 8.54 & 8.56 & Rossi et al., 2017 \\
\hline
\end{tabular}


Velázquez-Libera et al.

Modeling of Sigma Receptor Ligands

TABLE 1 | Continued

ID

Structure

Experimental

Predicted

References

$\mathrm{pKi}^{\mathrm{b}}$

$\mathrm{pKi}^{\mathrm{b}}$<smiles>COc1cccc([C@@H](C)CCN2CCOCC2)c1</smiles>

$67^{a}$<smiles>C[C@H](CCN(C)C)c1ccccc1</smiles>

6.86

7.25

Ross et al., 2017

68<smiles>C[C@H](CCN1CCCCC1)c1ccccc1</smiles>

6.37

6.35

Ross et al., 2017

69<smiles>C[C@H](CCN1CCC(Cc2ccccc2)CC1)c1ccccc1</smiles>

7.34

7.37

Ross et al., 2017

$70^{a}$<smiles>C[C@H](CCN1CCC(Cc2ccccc2)CC1)c1ccccc1</smiles>

8.54

8.62

Rossi et al., 2017

71<smiles>C[C@H](CCN1CCOCC1)c1ccccc1</smiles>

8.52

8.45

Ross et al., 2017

$72^{\mathrm{a}}$<smiles>C[C@@](O)(CCN1CCC(Cc2ccccc2)CC1)c1ccc2ccccc2c1</smiles>

7.07

6.56

Ross et al., 2017

73<smiles>C[C@@](O)(CCN1CCC(Cc2ccccc2)CC1)c1ccc2ccccc2c1</smiles>

8.00

8.01

Ri et al., 2016

74<smiles>C[C@@](O)(CCN1CCC(Cc2ccccc2)CC1)c1ccccc1</smiles>

7.96

7.92

Rui et al., 2016

75<smiles>C[C@@](O)(CCN1CCC(Cc2ccccc2)CC1)c1ccccc1</smiles>

7.57

7.73

hui et al., 2016

76

76

7.45

Ri et al., 2016

(Continued)

Frontiers in Chemistry | www.frontiersin.org

10

July 2019 | Volume 7 | Article 496 
TABLE 1 | Continued

\begin{tabular}{|c|c|c|c|c|}
\hline ID & Structure & $\begin{array}{l}\text { Experimental } \\
\text { pKi }^{\mathbf{b}}\end{array}$ & $\begin{array}{l}\text { Predicted } \\
\text { pKi }^{\mathbf{b}}\end{array}$ & References \\
\hline 77 & $\mathrm{HO}$ & 7.15 & 7.09 & Rui et al., 2016 \\
\hline 78 & $\mathrm{HO}$ & 7.21 & 7.18 & Rui et al., 2016 \\
\hline $80^{\mathrm{a}}$ & $\mathrm{HO}^{-}$ & 7.89 & 7.19 & Rui et al., 2016 \\
\hline
\end{tabular}

${ }^{a}$ Test set compounds.

${ }^{b}$ Experimental and predicted pKi values using Model SE.

and the more precise Glide XP was used for finding the final docking poses.

After several poses were found for each compound, the ones that showed the best scoring energies were considered. The information of PD144418, 4-IBP, haloperidol, NE-100, and (+)pentazocine in the crystallographic structures recently reported (Schmidt et al., 2016, 2018) was considered for the selection of the best solutions; these compounds show how the previously reported pharmacophoric pattern (Glennon, 2005) is oriented inside the S1R binding site. The essential chemical interactions described for analog ligands (ECIDALs) (Muñoz-Gutierrez et al., 2016; Ramírez and Caballero, 2018) defined for S1R ligands were identified using this information. The most obvious essential chemical interaction is that charged amino group of the ligands must be close to the side chain carboxylate group of the residue Glu172, forming an electrostatic interaction. Therefore, the best docking solution for each compound was the pose that had the best scoring energy and complies with this essential chemical interaction.

The "Interaction Fingerprints Panel" of Maestro (Maestro 10.2.011, Schrödinger LLC) was used for deriving the Interaction fingerprints (IFPs) as described in Singh et al. reports (Deng et al., 2004; Singh et al., 2006). The method accounts for the presence of different types of chemical interactions between ligands and the binding site residues of the target receptor by using bits. For this purpose, distance cutoffs are defined for the binding site, and the interacting set encompasses the residues that contain atoms within the specified cutoff distance from ligand atoms. An interaction matrix is constructed including the bits with relevant information of the defined chemical interactions.

\section{QSAR Modeling}

After docking experiments, 3D-QSAR models were performed to explain the SAR of the RC-33 analogs. Their bioactive conformations predicted by using docking were used as the alignment rule for deriving the models. The structural features that affect their activities against the S1R were identified by describing steric and electrostatic fields.

The 80 compounds dataset was randomly partitioned into training (64 compounds) and external (16 compounds) sets. A homogenous distribution of the activities was granted in both training and test sets. 3D-QSAR models were generated using Open3DQSAR (Tosco and Balle, 2011), an open access tool with all the capacities to construct 3D-QSAR models. Steric and electrostatic fields were computed according to classical molecular mechanics equations using the Merck Molecular Force Field (Halgren, 1996).

The field variables were calculated by describing the interaction energies between probe atoms $\left(\mathrm{sp}^{3}\right.$ carbon atoms with a charge +1 ) and structures in a $1.0 \AA$ step size grid box surrounding the whole set. Variables were processed as follows: (i) high energies adopted the top value of $30 \mathrm{kcal} / \mathrm{mol}$, (ii) energy values very close to zero (below $0.05 \mathrm{kcal} / \mathrm{mol}$ ) were set to zero in order to reduce noise, (iii) variables which only assumed a few different values ( $n$-level variables) were removed. Thereafter, variables were scaled using the Block Unscaled Weighting procedure (Kastenholz et al., 2000; Boháč et al., 2002) and the predictive power of the models was improved by using the Smart Region Definition algorithm (Pastor et al., 1997).

Partial Least Square (PLS) regression was used to construct 3D-QSAR models, including from one to five Principal Components (PCs) and different combinations of fields. Models 
were derived by using one field and by combining them; the best model was selected by considering the higher value of the internal leave-one-out (LOO) cross-validation $Q^{2}$.

\section{RESULTS AND DISCUSSION}

\section{Docking Predictions}

We have a structural information of the binding poses of S1R ligands such as PD144418, 4-IBP, haloperidol, and NE100 that similar in shape to RC-33. This information was used for evaluating the quality of the obtained docking results for RC-33 and its analogs. It is known that S1R ligands contain a charged nitrogen central atom flanked by two hydrophobic regions of different size (Glennon, 2005). The above mentioned S1R ligands form electrostatic interactions between the ligand charged nitrogen atoms and the side chain carboxylate of Glu172. In addition, their larger hydrophobic groups locate near the residues Val84, Met93, Leu95, Leu105, Tyr206, Ile178, Leu182, and Tyr103 (primary hydrophobic site), and their smaller hydrophobic groups locate near the residues Phe107, Trp164, His154, and Ile124 (secondary hydrophobic site). It is expected that the studied compounds establish such interactions.

Docking orientations of RC-33 and its analogs are represented in Figure 1. The best docking pose obtained for RC-33 was compared with the orientations of PD144418, 4-IBP, haloperidol, NE-100, and (+)-pentazocine in the reference crystallographic structures $5 \mathrm{HK} 1,5 \mathrm{HK} 2,6 \mathrm{DJZ}, 6 \mathrm{DK} 0$, and $6 \mathrm{DK} 1$, respectively. (+)-Pentazocine is an agonist as RC-33, but it is shorter than RC-33 and the other crystallized ligands; therefore, it is the least suitable ligand for the structural comparison between the crystallized ligands and the docked RC-33 analogs. Figure 1A shows that the docked structure of RC-33 was similarly oriented as the other crystallized ligands. On the other hand, Figure 1B shows that suitable binding modes of the ligands were found for all the RC-33 analogs. All of them form the conserved salt bridge between the charged $\mathrm{N}$ atom of the ligands and the residue Glu172 of the S1R. They also oriented their large hydrophobic groups to the primary hydrophobic site, and oriented their small hydrophobic groups to the secondary hydrophobic site. Representations in Figure 1 show that our docking poses are similar to the S1R-ligand X-ray structures reported to date.

We calculated RMSD values for the studied compounds with respect to the docking result of RC-33 inside the S1R by using an in-house script (Velázquez-Libera et al., 2018). These calculations show the similarity in orientations between RC-33 and its analogs in an easy way. Since the RC-33 derivatives are different from the reference compound, RMSD values were calculated by considering only the common graphs between molecules. \%RefMatch and \%MolMatch values were defined, where \%RefMatch refers to the percent of common graphs between the docked compound and RC-33 regarding the total number of atoms of RC-33; meanwhile, \%MolMatch refers to the percent of common graphs between the docked compound, and RC-33 regarding the total number of atoms of the docked compound. These values allow identifying the maximal similitude between the docked compound and RC-33; therefore, an RMSD value with high \%RefMatch and \%MolMatch

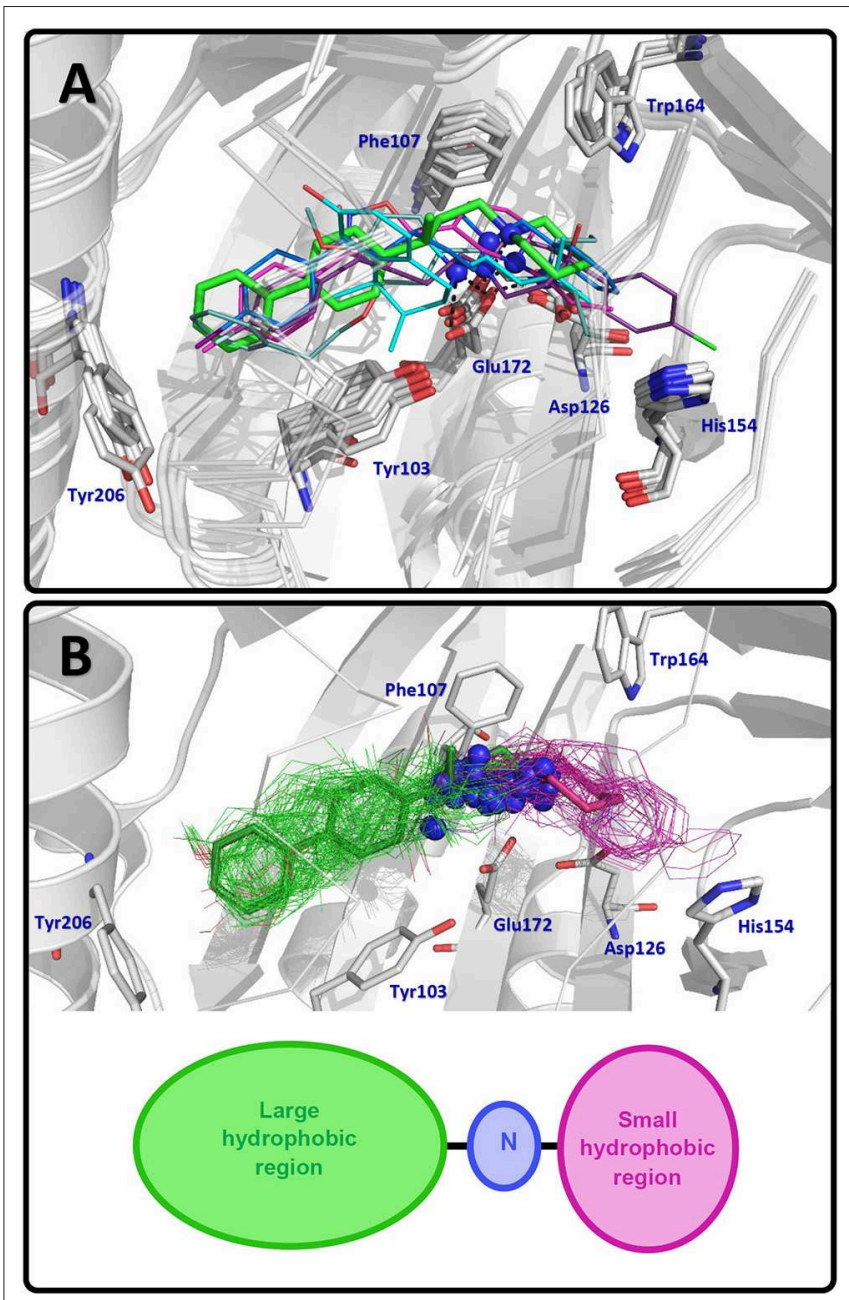

FIGURE 1 | Docking results for RC-33 and its analogs. (A) Docking pose obtained for RC-33 (stick representation in green) and comparison with X-ray crystallographic structures of the antagonist PD144418 (thin stick representation in purple, PDB code 5HK1), the ambiguous ligand 4-IBP (thin stick representation in light blue, PDB code 5HK2), the antagonist haloperidol (thin stick representation in lilac, PDB code 6DJZ), the antagonist NE-100 (thin stick representation in teal, PDB code 6DKO), and the agonist (+)-pentazocine (thin stick representation in cyan, PDB code 6DK1). N positively charged atom for each compound is represented by a blue sphere. (B) (top) Docking of RC-33 (in sticks representation) and comparison with its analogs (in lines representation); for each compound large hydrophobic group is in green at the left, small hydrophobic group is in purple at the right, and N positively charged atom is a sphere in blue. (bottom) Pharmacophoric model for S1R ligands: $\mathrm{N}$ positively charged atom (blue) flanked by large hydrophobic (green) and small hydrophobic (purple) regions.

values reflects that the compound under analysis bears a strong resemblance with RC-33.

The majority of the compounds under study have the 1(3-phenylbutyl)piperidine or parts of this group in common with RC-33. Their RMSD values are reported in Table 2. In general, RMSD values reflect that the majority of compounds had the 1-(3-phenylbutyl)piperidine (or part of this group) similarly oriented with respect to RC-33 (RMSD $<2 \AA$ ). However, 
TABLE 2 | RMSD values of the obtained docking pose common fragments for the studied compounds with respect to the docking result of RC-33 inside the S1R.

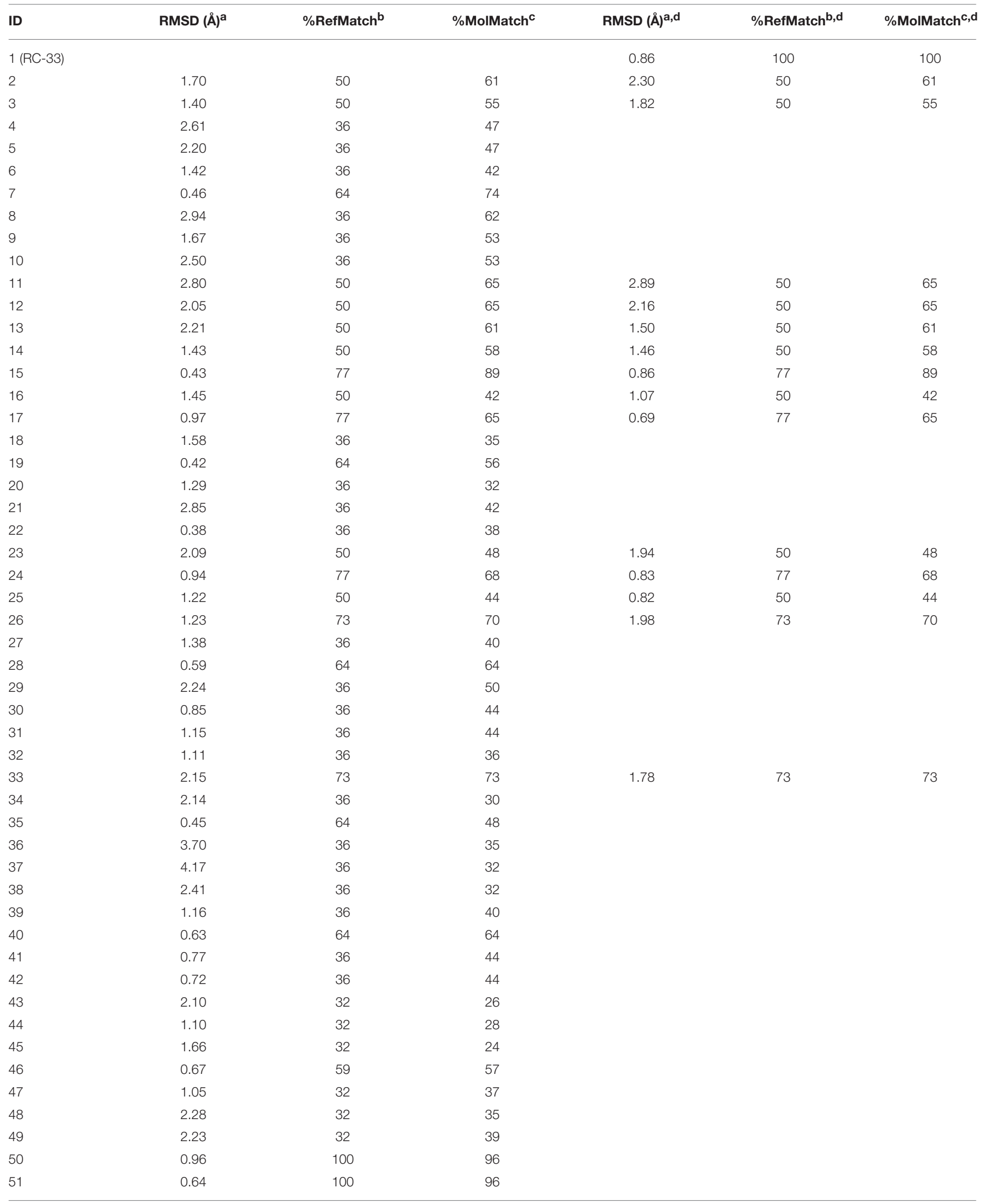


TABLE 2 | Continued

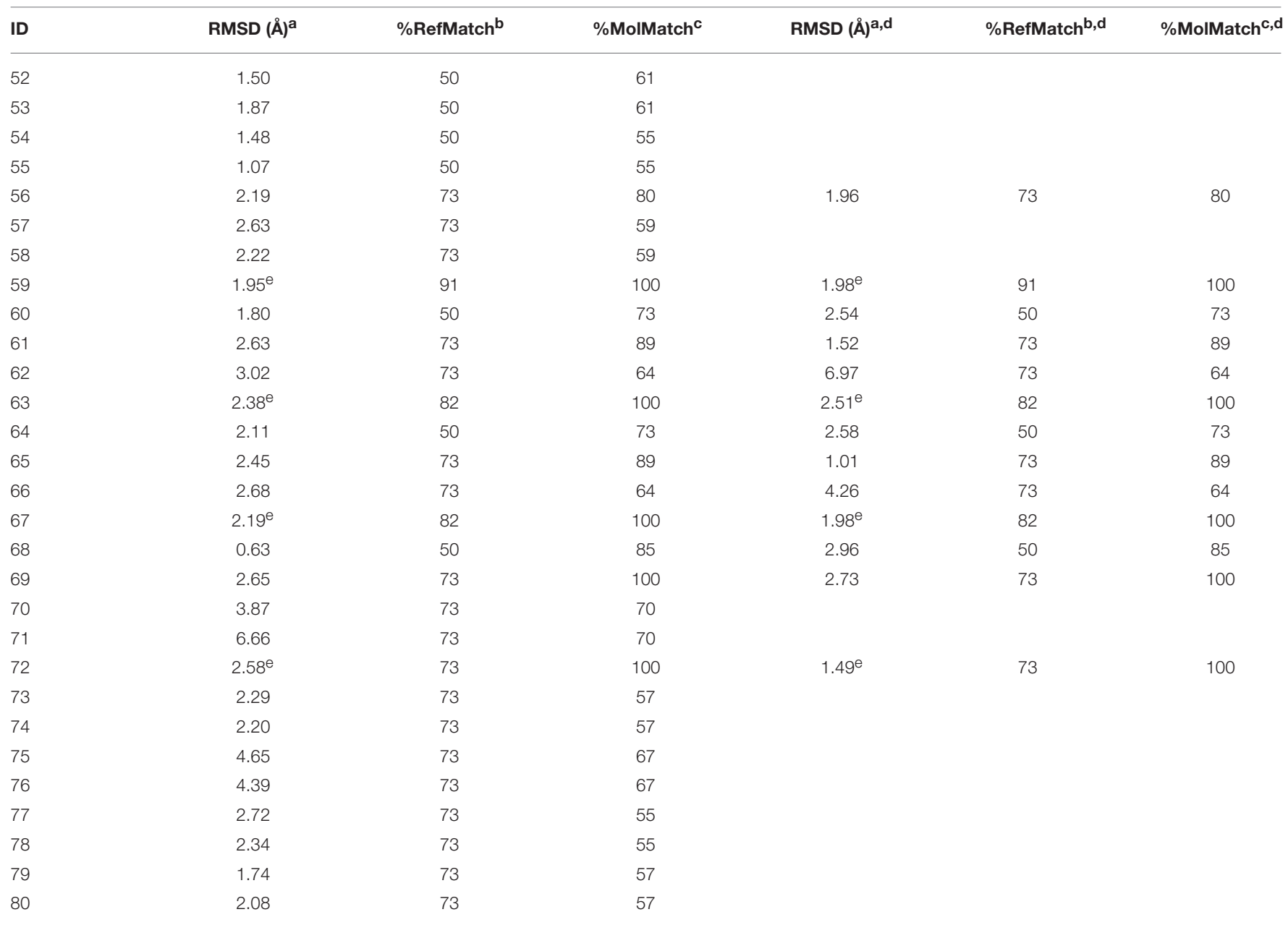

${ }^{a} R M S D$ values considering only the common chemical fragments between the docked compound and the reference compound $R C$-33.

$b \%$ RefMatch refers to the percent of common graphs between the docked and reference compound RC-33 concerning the total number of atoms of the reference compound $R C$-33. c\%MolMatch refers to the percent of common graphs between the docked and reference compound RC-33 regarding the total number of atoms of the docked compound.

${ }^{d} R M S D, \%$ RefMatch, and \%MolMatch values for the $S$ enantiomer of the compounds reported as racemic pairs.

eIn this case, difference in ring heavy atoms were not considered between the docked compound and the reference compound RC-33.

Table 2 reports compounds with RMSD > $2.5 \AA$ (for instance, compounds 11 ( $\mathrm{R}$ and $\mathrm{S}), \mathbf{5 7}, 60$ (S), and 77). The 1-(3phenylbutyl)piperidine group of these compounds is displaced toward the helices $\alpha 4$ and $\alpha 5$; however, their amine groups keep the salt bridge interaction with the residue Glu172. In addition, we found in Table 2 compounds with RMSD > $4 \AA$ (for instance, compounds 37, $62(\mathrm{~S}), 66$ (S), 75, and 76). The 1(3-phenylbutyl)piperidine group of these compounds is oriented to the reverse with respect to this group in RC-33; their amine groups also keep the salt bridge interaction with the residue Glu172. These compounds have larger hydrophobic substituents at position 4 of the piperidine, increasing the size of this group. The changed groups fit better inside the bigger hydrophobic cavity close to the helices $\alpha 4$ and $\alpha 5$ when their orientations are opposed to the orientation of the 1-(3-phenylbutyl)piperidine group in RC-33. In this way, these compounds are also adapted to the previous described pharmacophore pattern for S1R ligands
(Ablordeppey et al., 2000; Glennon, 2005; Caballero et al., 2012) (the $\mathrm{N}$ positively charged atom flanked by two hydrophobic groups of different sizes), where the charged atom is salt-bridged to Glu172, the bigger hydrophobic group is placed near the helices $\alpha 4$ and $\alpha 5$ at the membrane proximal, and the smaller hydrophobic group is placed near the narrow end of the cupin barrel that is further from the membrane.

The chemical interactions between the RC-33 analogs and the residues at the $\mathrm{S} 1 \mathrm{R}$ binding site can be described in detail by using IFPs. This method has been commonly used for identifying the relevant residues involved in protein-ligand affinities (Caballero et al., 2018; Navarro-Retamal and Caballero, 2018; Velázquez-Libera et al., 2018). IFPs capture and label the chemical contacts between a target protein and a set of its ligands as a whole. The chemotypes are identified with the following labels: P (polar groups), H (hydrophobic groups), A (hydrogen bonds where the residue is the acceptor), D (hydrogen bonds 
where the residue is the donor), Ar (aromatic groups), and Ch (electrostatic interactions with charged groups). IFPs also differentiate between contacts with backbone and contacts with side-chain functional groups. We calculated IFPs by considering the S1R-ligand complexes formed by our docked structures.

The calculated IFPs are reported in Figure 2. The IFP analysis applied to the complexes between S1R and the RC-33 analogs obtained by docking revealed that 29 S1R residues had contacts with ligands. These residues and their positions in the S1R secondary structure are depicted in Figure 2A. The S1R binding site is mainly hydrophobic; in fact, the vast majority of the observed interactions are hydrophobic or aromatic when analyzing the occurrence of chemical contacts in the studied structures (Figure 2C).

The residues with polar interactions were identified in the plots of percent of occurrence obtained from IFP calculations (Figure 2). The residue E172 at the sheet $\beta 10$ has polar contributions in $100 \%$ of the total structures, forming a saltbridge and it also acts as HB acceptor in $80 \%$ of the studied structures. The residue D126 at the sheet $\beta 5$ was identified with polar contributions in more than $50 \%$ of the studied structures. The residue T181 at the helix $\alpha 4$ has polar contributions in more than $80 \%$ of the studied structures. Finally, the residues S117 (backbone and side chain), H154 (side chain), and T202

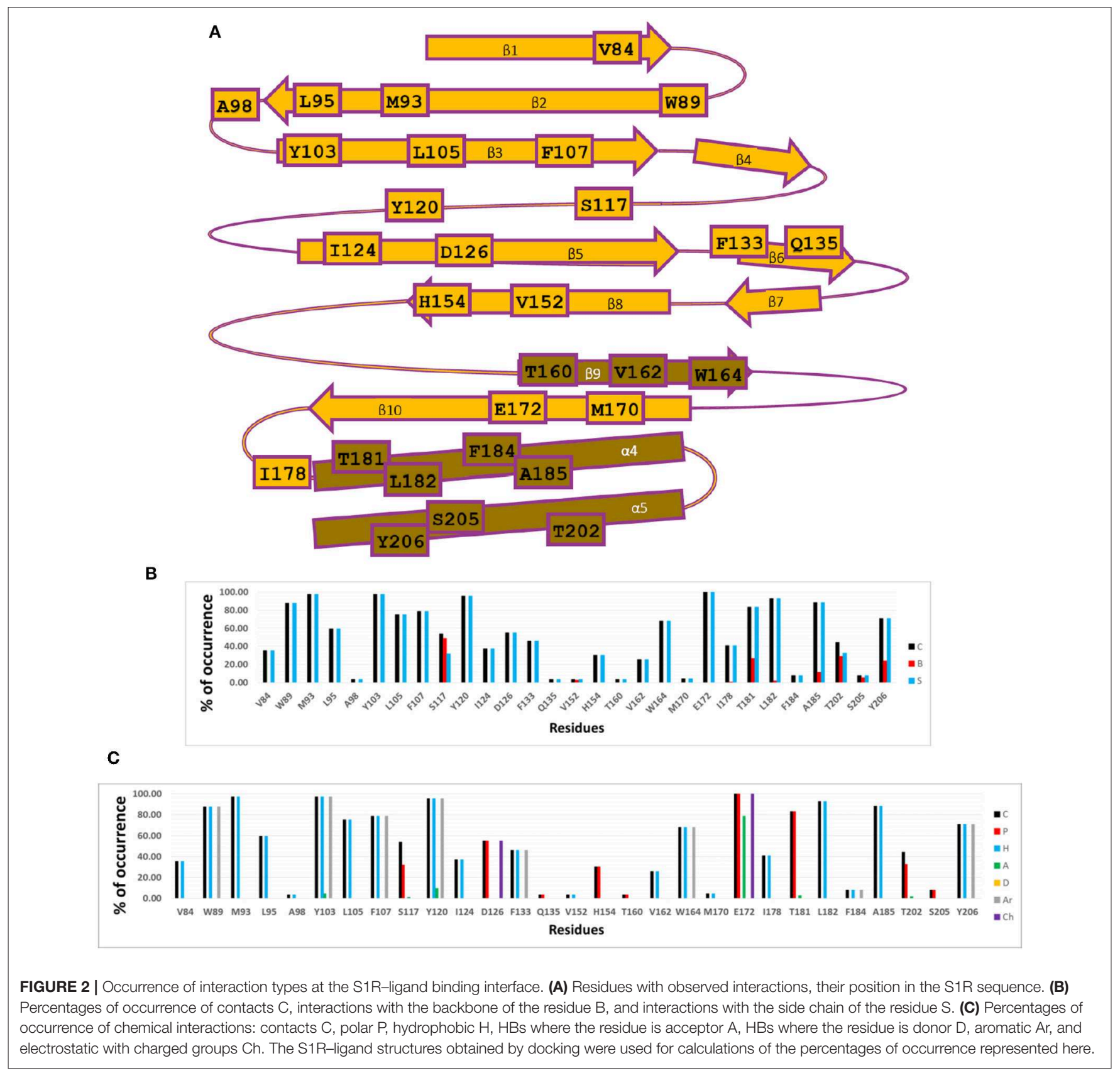


TABLE 3 | Statistical information of the 3D-QSAR models.

\begin{tabular}{lccccccccc}
\hline Fields & $\mathbf{N C}$ & $\boldsymbol{R}^{\mathbf{2}}$ & $\boldsymbol{S}$ & $\boldsymbol{Q}^{\mathbf{2}}$ & $\boldsymbol{S}_{\text {LOO }}$ & $\boldsymbol{R}_{\text {test }}^{\mathbf{2}}$ & $\boldsymbol{S}_{\text {test }}$ & $\% \boldsymbol{S}$ & $\% \mathrm{E}$ \\
\hline $\mathrm{S}$ & 8 & 0.98 & 0.13 & 0.64 & 0.54 & 0.34 & 0.81 & 1 & \\
$\mathrm{E}$ & 4 & 0.81 & 0.39 & 0.54 & 0.62 & 0.59 & 0.63 & - & 1 \\
SE & 7 & 0.97 & 0.15 & 0.70 & 0.50 & 0.61 & 0.62 & 0.88 & 0.12
\end{tabular}

$N C$ is the number of components; $S$ is the standard deviation of the fitted activity of the training set; $R^{2}, Q^{2}$, and $R_{\text {test }}^{2}$ are the coefficients of correlation of the training set, $L O O$ cross validation, and test set, respectively; $S_{L O O}$ is the standard deviation of the LOO cross validation, and $S_{\text {test }}$ is the standard deviation of the test predictions. $\% S$ and $\% E$ are the relative contributions of the steric $(S)$ and the electrostatic $(E)$ fields, respectively.

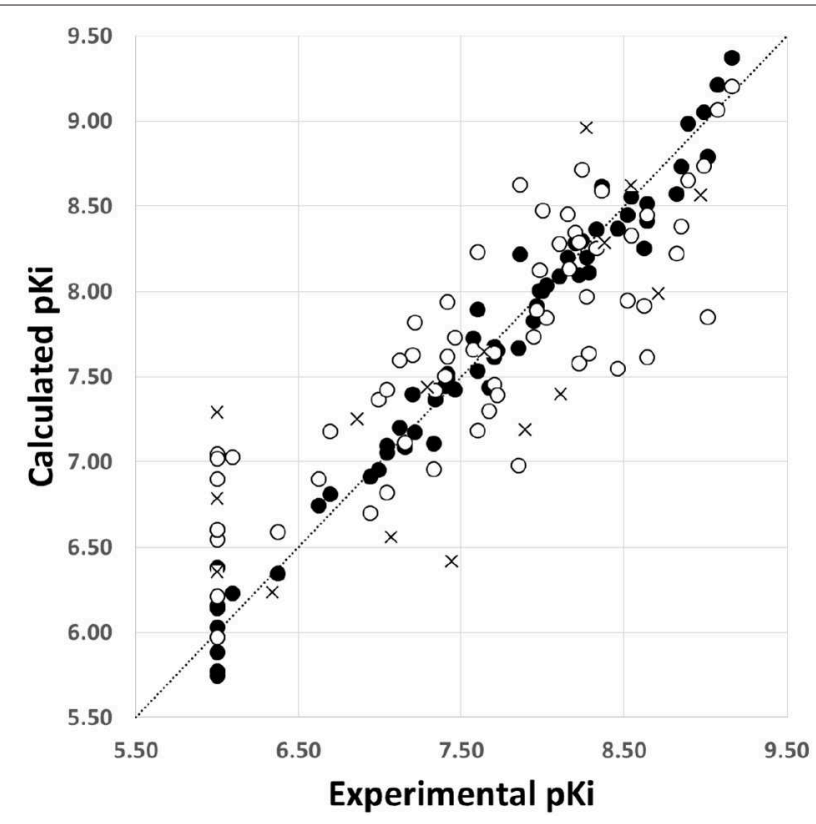

FIGURE 3 | Scatter plot of the experimental activities vs. predicted activities for the model SE: $(\bullet)$ training set predictions, (०) LOO cross-validation predictions, and $(x)$ test set predictions.

(backbone and side chain) have polar contributions in around $30 \%$ of the studied structures.

Several residues with aromatic interactions were also identified in the plots of percent of occurrence obtained from IFP calculations (Figure 2). The residues with aromatic interactions were important for the shape of the S1R binding site because they restrict the space of the pockets. Four aromatic residues located at the center of the binding site (W89, Y103, F107, and Y120) were identified by the IFP calculations with percent of occurrence values above $80 \%$. These residues cause a bottleneck just in front of the residue E172; therefore they could help to orient the positively charged $\mathrm{N}$ of the ligands to form the salt bridge. At the same time, they could stabilize the presence of the positive charge by means of $\pi$-cation interactions. The aromatic residues F133 at the sheet $\beta 6$ and $\mathrm{W} 164$ the sheet $\beta 9$, located close to the narrower end of the cupin $\beta$-barrel, have percent of occurrence values of 50 and $70 \%$, respectively. On the other hand, the residue Y206, located at the helix $\alpha 5$, has a percent of occurrence value of $70 \%$.

The remaining residues with hydrophobic interactions were also identified in the plots of percent of occurrence obtained from IFP calculations (Figure 2). The residues identified with percent of occurrence above 75\% M93 (at $\beta 2$ ), L105 (at $\beta 3$ ), and L182/A185 (at $\alpha 4$ ) are located at the bigger hydrophobic pocket. The residues V84 (at $\beta 1$ ), L95 (at $\beta 2$ ), and I178 (at the loop between $\beta 10$ and $\alpha 4$ ) are also located at the bigger hydrophobic pocket and were identified by IFP calculations with lower percent of occurrences, and the residue I124 at $\beta 5$, located at the smaller hydrophobic pocket, had a percent of occurrence below $40 \%$.

In general, the reported IFPs identify the most important S1R residues which establish chemical interactions with RC-33 analogs. Furthermore, it could be useful for the understanding of the interactions between S1R and its ligands.

\section{D-QSAR Results}

We constructed the 3D-QSAR models based on docking alignment; therefore, the docked structures were included in a box for creating the relevant fields, since they are models of the ligand conformations inside the S1R binding site. The docking-based or receptor-guided alignment 3D-QSAR is a welldocumented method in literature (Guasch et al., 2012; NavarroRetamal and Caballero, 2016; Muñoz-Gutiérrez et al., 2017). Three 3D-QSAR models were trained using the steric field (Model S), the electrostatic field (Model E), and the combination of both fields (Model SE). The most reliable models were selected by measuring the LOO cross-validation performance $\left(Q^{2}>0.5\right)$ and the test set predictions $\left(R_{\text {test }}^{2}>0.5\right)$.

Table 3 lists the description and statistical information of the best 3D-QSAR models. This report proved that model $\mathrm{S}$ has better (LOO) cross-validation $Q^{2}$ than model E. However, when both steric and electrostatic fields are tied together in the more complex model SE, the $Q^{2}$ value increases; therefore, this model, which had a $Q^{2}=0.70$ including seven components, containing a major contribution of the steric field (88\%), was identified as the model best describing the structure-activity relationship of the studied RC-33 analogs. These results reflect that the steric features are mandatory for modulating the agonistic activities of the studied compounds. This is reasonable considering that the S1R binding site is mostly hydrophobic.

The model SE explains $97 \%$ of the variance and has a low standard deviation $(S=0.15)$. The predictions of $\mathrm{pKi}$ values for the $64 \mathrm{RC}-33$ analogs in the training set using the model SE are reported in Table 1 and the correlations between the predicted and experimental pKi values (from training and LOO cross validation) are shown in Figure 3. It is possible to observe that the selected model fitted adequately the whole dataset; it is noteworthy that the more potent compounds had an outstanding performance. When the model SE was used to predict the $\mathrm{pKi}$ values of the test set compounds, well results were also found, reflected by the value of $R_{\text {test }}^{2}=0.61$. The predicted $\mathrm{pKi}$ values for the test set are listed in Table $\mathbf{1}$, and the correlation between the calculated and experimental $\mathrm{pKi}$ values are plotted in Figure 3. 


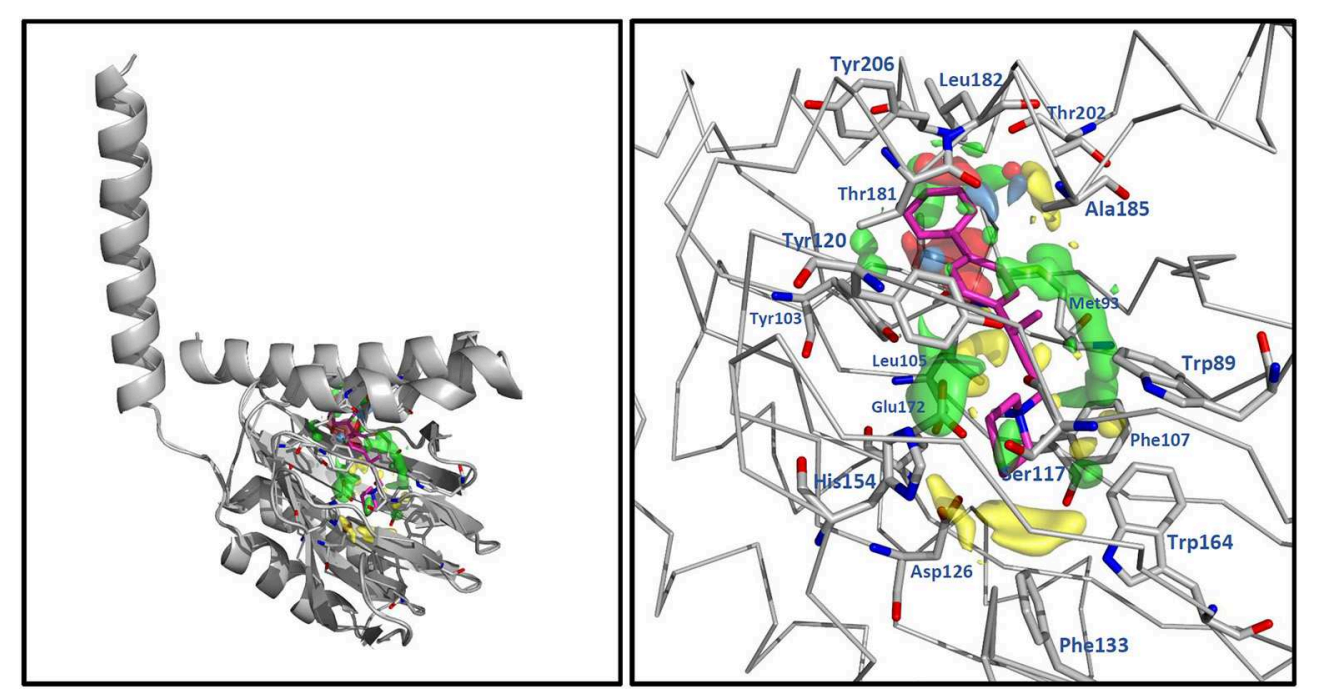

FIGURE 4 | 3D-QSAR contour maps for the RC-33 analogs (model SE). The steric field is represented by green and yellow isopleths: the green ones indicate regions where bulky groups enhance the activity, and the yellow ones indicate regions where bulky groups disfavor the activity. The electrostatic field is represented by blue and red isopleths: the blue ones indicate regions where an increase of positive charge enhances the activity and the red ones indicate regions where an increase of negative charge enhances the activity. $\mathrm{RC}-33$ is shown inside the fields.

Figure 4 shows contour plots of the steric and electrostatic fields projected onto the docked structure of RC-33 for association between the fields, the compounds of the whole set, and the residues at the S1R binding site. In this figure, green and yellow contours represent regions with positive and negative steric components, respectively. It is noted that positive steric components have a major role. A great green contour in front of the 3-phenylbutylamine, and near the residues V84, W89, F107, and A185, indicates that bulk groups are desired in this region. It is noteworthy that the most active compounds such as RC-33, 7, 15, 27, 28, and 33 has the methyl group of the 3-phenylbutylamine in this region, but the majority of the less active compounds such as $\mathbf{8}, \mathbf{2 9}, \mathbf{4 1}, \mathbf{6 4}$, and $\mathbf{6 7}$ have this group deeper into the bigger hydrophobic pocket. Another three green contours are located near the piperidine of RC-33 and the residues Y120, S117, and W164 indicating that this group or another bulky group in this region is needed. In general, compounds with a dimethylamine in this region (compounds 2-15) are less active than similar compounds that contain piperidine. Another green contour near the residues Y103 and E172 reflects that several active compounds contain the methyl group of the 3-phenylbutylamine in this region. Another green contours are located at the bigger hydrophobic pocket near the residues Y103, Y206, and T202, indicating the preference of a bulky group in this region. For instance, the biphenyl group in compound 7 is preferred instead the phenyl group in compound 8 because the former group fills the entire space of the bigger hydrophobic pocket. Several yellow contours were identified near the residues W164, L105, F107, and T202. All of them are close to the green contours both in the bigger and smaller pockets, and reflect the complexity of the steric field inside the S1R binding site.
In Figure 4, blue and red contours represent regions with positive and negative electrostatic components, respectively; all of them are small and are located inside the bigger hydrophobic pocket. The blue contours are near the residues T181, A185, L182, and the backbone of Y206, and the red contours are near the residues A92, L95, L105, L182, and T202. The blue contours are located in regions where ligands placed hydroxyl groups and their pKi values are between 7 and 7.8 (moderate activities). For instance, compounds $\mathbf{1 3}$ and 77 have hydroxyl close to the backbone of Y206, 75, and $\mathbf{7 6}$ have hydroxyl close to A185, and 53, 55, and $\mathbf{7 8}$ have hydroxyl close to T181. The red contours are located in regions where ligands placed OMe groups and the activity is increased. For instance, compounds 22 and $\mathbf{3 0}$ that contain OMe have better activities than compounds 21 and 29 without this group.

The docking-based 3D-QSAR methodology allows establishing a comparison between the chemical features that describe the structure-activity relationship of bioactive ligands and the protein binding site (Alzate-Morales and Caballero, 2010; Caballero et al., 2011; Quesada-Romero et al., 2014; Mena-Ulecia et al., 2015; Muñoz-Gutiérrez et al., 2017). The contour plots in receptor-based 3D-QSAR are not receptor maps, but they solve another key point of the description of the differential activities: different potency in activities is connected with different chemical environments and interactions. The docking and 3D-QSAR methods applied to the study of RC-33 analogs give more information about the structure of S1R-ligand complexes, and identify important chemical features to take into account in the future design of potent S1R ligands. We feel that another similar studies on other series of compounds will be reported during next years. 


\section{CONCLUSION}

This is the first structure-based molecular modeling investigation a few years after the elucidation of the S1R crystallographic structure; therefore, details of the binding poses and the chemical interactions in the binding site are described. Binding orientations and structure-activity relationship of RC-33 analogs as S1R agonists were studied by using molecular docking and 3D-QSAR methods.

Docking poses obtained for the studied compounds inside the S1R binding site explain the interactions between the well-known theoretical pharmacophore model reported for these compounds (elucidated before the knowledge of the S1R 3D structure) and the residues located at the binding site. They also reproduced structural features reported for complexes between S1R and PD144418, 4-IBP, and other active ligands. The docking analysis, including the IFP calculations, confirmed the preponderant role of E172 forming a salt bridge with the positively charged $\mathrm{N}$ of the ligands. Furthermore, docking experiments also identified the importance role of the aromatic residues delimiting the shape of the S1R binding site: specifically, W89, Y103, F107, and Y120 which are at the center of the binding site, F133 and W164 which are close to the narrower end of the cupin $\beta$-barrel, and Y206 which is close to the helix $\alpha 5$.

A receptor-guided alignment $3 \mathrm{D}$-QSAR model with adequate statistical significance and acceptable prediction power was obtained. Steric and electrostatic features had contributions to the differential potency of the agonists, with a major role of the steric ones. The 3D-QSAR model demonstrated that an implicit

\section{REFERENCES}

Ablordeppey, S. Y., Fischer, J. B., and Glennon, R. A. (2000). Is a nitrogen atom an important pharmacophoric element in sigma ligand binding? Bioorg. Med. Chem. 8, 2105-2111. doi: 10.1016/S0968-0896(00)00148-6

Almerico, A. M., Tutone, M., and Lauria, A. (2012). Receptor-guided 3D-QSAR approach for the discovery of c-kit tyrosine kinase inhibitors. J. Mol. Model. 18, 2885-2895. doi: 10.1007/s00894-011-1304-0

Alon, A., Schmidt, H. R., Wood, M. D., Sahn, J. J., Martin, S. F., and Kruse, A. C. (2017). Identification of the gene that codes for the $\sigma 2$ receptor. Proc. Natl. Acad. Sci. U.S.A. 114, 7160-7165. doi: 10.1073/pnas.1705154114

Alzate-Morales, J., and Caballero, J. (2010). Computational study of the interactions between guanine derivatives and cyclin-dependent kinase 2 (CDK2) by CoMFA and QM/MM. J. Chem. Inf. Model. 50, 110-122. doi: $10.1021 / \mathrm{ci} 900302 \mathrm{z}$

Amaning, K., Lowinski, M., Vallee, F., Steier, V., Marcireau, C., Ugolini, A., et al. (2013). The use of virtual screening and differential scanning fluorimetry for the rapid identification of fragments active against MEK1. Bioorg. Med. Chem. Lett. 23, 3620-3626. doi: 10.1016/j.bmcl.2013.04.003

Batra, J., Szabó, A., Caulfield, T. R., Soares, A. S., Sahin-Tóth, M., and Radisky, E. S. (2013). Long-range electrostatic complementarity governs substrate recognition by human chymotrypsin C, a key regulator of digestive enzyme activation. J. Biol. Chem. 288, 9848-9859. doi: 10.1074/jbc.M113. 457382

Boháč, M., Loeprecht, B., Damborský, J., and Schüürmann, G. (2002). Impact of Orthogonal Signal Correction (OSC) on the predictive ability of CoMFA models for the ciliate toxicity of nitrobenzenes. Q. Struct. Activit. Relationsh. 21,3-11. doi: 10.1002/1521-3838(200205)21:1<3::AID-QSAR3>3.0.CO;2-D

Caballero, J., Morales-Bayuelo, A., and Navarro-Retamal, C. (2018). Mycobacterium tuberculosis serine/threonine protein kinases: structural correlation is found in the data under analysis between the chemical features of the compounds in their active conformations and their interactions in the pockets of the S1R binding site.

Overall, the information reported here, derived from the recently reported S1R structure, will be useful for the future research in the design of novel S1R ligands.

\section{DATA AVAILABILITY}

The raw data supporting the conclusions of this manuscript will be made available by the authors, without undue reservation, to any qualified researcher.

\section{AUTHOR CONTRIBUTIONS}

The work was completed by cooperation of all authors. JC was responsible for the study of concept and design of the project. JV-L performed the docking RMSD analysis, IFPs, and 3D-QSAR calculations. GR and CN-R performed the docking calculations. $\mathrm{SC}$ and JC drafted and revised the manuscript.

\section{FUNDING}

This research was funded by FONDECYT Regular grant number 1170718 (JC) and FONDECYT Postdoc grant number 3170434 (CN-R). The authors gratefully acknowledge MIUR for the doctoral fellowship to GR and thankfully recognize Scuola di Alta Formazione Dottorale of University of Pavia for the mobility research scholarship provided to GR. information for the design of their specific ATP-competitive inhibitors. J. Comput. Aided Mol. Des. 32, 1315-1336. doi: 10.1007/s10822-018-0173-3

Caballero, J., Quiliano, M., Alzate-Morales, J. H., Zimic, M., and Deharo, E. (2011). Docking and quantitative structure-activity relationship studies for 3-fluoro-4-(pyrrolo[2,1-f][1,2,4] triazin-4-yloxy)aniline, 3-fluoro-4-(1Hpyrrolo[2,3-b]pyridin-4-yloxy)aniline, and 4-(4-amino-2-fluorophenoxy)-2pyridinylamine derivatives as c-Met kinase inhibitors. J. Comput. Aided Mol. Des. 25, 349-369. doi: 10.1007/s10822-011-9425-1

Caballero, J., Zilocchi, S., Tiznado, W., Rossi, D., and Collina, S. (2012). Models of the pharmacophoric pattern and affinity trend of methyl 2-(aminomethyl)1-phenylcyclopropane-1-carboxylate derivatives as $\sigma 1$ ligands. Mol. Simul. 38, 227-235. doi: 10.1080/08927022.2011.614243

Chu, U. B., and Ruoho, A. E. (2016). Biochemical pharmacology of the sigma-1 receptor. Mol. Pharmacol. 89, 142-153. doi: 10.1124/mol.115.101170

Collina, S., Bignardi, E., Rui, M., Rossi, D., Gaggeri, R., Zamagni, A., et al. (2017a). Are sigma modulators an effective opportunity for cancer treatment? A patent overview (1996-2016). Expert Opin. Ther. Pat. 27, 565-578. doi: 10.1080/13543776.2017.1276569

Collina, S., Loddo, G., Urbano, M., Linati, L., Callegari, A., Ortuso, F., et al. (2007). Design, synthesis, and SAR analysis of novel selective [sigma]1 ligands. Bioorg. Med. Chem. 15, 771-783. doi: 10.1016/j.bmc.2006.10.048

Collina, S., Rui, M., Stotani, S., Bignardi, E., Rossi, D., Curti, D., et al. (2017b). Are sigma receptor modulators a weapon against multiple sclerosis disease? Future Med. Chem. 9, 2029-2051. doi: 10.4155/fmc-2017-0122

DeCoster, M. A., Klette, K. L., Knight, E. S., and Tortella, F. C. (1995). o receptormediated neuroprotection against glutamate toxicity in primary rat neuronal cultures. Brain Res. 671, 45-53. doi: 10.1016/0006-8993(94)01294-R

Deng, Z., Chuaqui, C., and Singh, J. (2004). Structural interaction fingerprint (SIFt): a novel method for analyzing three-dimensional protein-ligand binding interactions. J. Med. Chem. 47, 337-344. doi: 10.1021/jm030331x 
Friesner, R. A., Banks, J. L., Murphy, R. B., Halgren, T. A., Klicic, J. J., Mainz, D. T., et al. (2004). Glide: a new approach for rapid, accurate docking and scoring. 1. Method and assessment of docking accuracy. J. Med. Chem. 47, 1739-1749. doi: $10.1021 / \mathrm{jm} 0306430$

Furuse, T., and Hashimoto, K. (2010). Sigma-1 receptor agonist fluvoxamine for delirium in patients with Alzheimer's disease. Ann. Gen. Psychiatry 9:6. doi: 10.1186/1744-859X-9-6

Glennon, R. A. (2005). Pharmacophore identification for sigma-1 (sigma1) receptor binding: application of the "deconstructionreconstruction-elaboration” approach. Mini Rev. Med. Chem. 5, 927-940. doi: $10.2174 / 138955705774329519$

Glennon, R. A., Ismaiel, A. M., Ablordeppey, S., El-Ashmawy, M., and Fisher, J. B. (2004). Thioxanthene-derived analogs as sigma(1) receptor ligands. Bioorg. Med. Chem. Lett. 14, 2217-2220. doi: 10.1016/j.bmcl.2004.02.018

Guasch, L., Sala, E., Valls, C., Mulero, M., Pujadas, G., and Garcia-Vallvé, S. (2012). Development of docking-based 3D-QSAR models for PPARgamma full agonists. J. Mol. Graph. Model. 36, 1-9. doi: 10.1016/j.jmgm.2012.03.001

Hajipour, A. R., Fontanilla, D., Chu, U. B., Arbabian, M., and Ruoho, A. E. (2010). Synthesis and characterization of N,N-dialkyl and N-alkyl-Naralkyl fenpropimorph-derived compounds as high affinity ligands for sigma receptors. Bioorg. Med. Chem. 18, 4397-4404. doi: 10.1016/j.bmc.2010.04.078

Halgren, T. A. (1996). Merck molecular force field. II. MMFF94 van der Waals and electrostatic parameters for intermolecular interactions. J. Comput. Chem. 17, 520-552. doi: 10.1002/(SICI)1096-987X(199604)17:5/6\&lt;520::AIDJCC2\&gt;3.0.CO;2-W

Hanner, M., Moebius, F. F., Flandorfer, A., Knaus, H. G., Striessnig, J., Kempner, E., et al. (1996). Purification, molecular cloning, and expression of the mammalian sigma1-binding site. Proc. Natl. Acad. Sci. U.S.A. 93, 8072-8077. doi: 10.1073/pnas.93.15.8072

Hashimoto, K. (2009). Can the sigma-1 receptor agonist fluvoxamine prevent schizophrenia? CNS Neurol. Disord. Drug Targets 8, 470-474. doi: $10.2174 / 187152709789824633$

Hayashi, T., and Su, T.-P. (2004). Sigma-1 receptor ligands: potential in the treatment of neuropsychiatric disorders. CNS Drugs 18, 269-284. doi: 10.2165/00023210-200418050-00001

Kastenholz, M. A., Pastor, M., Cruciani, G., Haaksma, E. E., and Fox, T. (2000). GRID/CPCA: a new computational tool to design selective ligands. J. Med. Chem. 43, 3033-3044. doi: 10.1021/jm000934y

Marra, A., Rossi, D., Pignataro, L., Bigogno, C., Canta, A., Oggioni, N., et al. (2016). Toward the identification of neuroprotective agents: g-scale synthesis, pharmacokinetic evaluation and CNS distribution of (R)-RC-33, a promising SIGMA1 receptor agonist. Future Med. Chem. 8, 287-295. doi: $10.4155 /$ fmc. 15.191

Martin, W. R., Eades, C. G., Thompson, J. A., Huppler, R. E., and Gilbert, P. E. (1976). The effects of morphine- and nalorphine- like drugs in the nondependent and morphine-dependent chronic spinal dog. J. Pharmacol. Exp. Ther. 197, 517-532.

Mavlyutov, T. A., Guo, L.-W., Epstein, M. L., and Ruoho, A. E. (2015). Role of the sigma-1 receptor in Amyotrophic Lateral Sclerosis (ALS). J. Pharmacol. Sci. 127, 10-16. doi: 10.1016/j.jphs.2014.12.013

Mena-Ulecia, K., Tiznado, W., and Caballero, J. (2015). Study of the differential activity of thrombin inhibitors using docking, QSAR, molecular dynamics, and MM-GBSA. PLoS ONE 10:e0142774. doi: 10.1371/journal.pone.0142774

Meyer, D. A., Carta, M., Partridge, L. D., Covey, D. F., and Valenzuela, C. F. (2002). Neurosteroids enhance spontaneous glutamate release in hippocampal neurons possible role of metabotropic $\sigma 1$-like receptors. J. Biol. Chem. 277, 28725-28732. doi: 10.1074/jbc.M202592200

Mishina, M., Ishiwata, K., Ishii, K., Kitamura, S., Kimura, Y., Kawamura, K., et al. (2005). Function of sigmal receptors in Parkinson's disease. Acta Neurol. Scand. 112, 103-107. doi: 10.1111/j.1600-0404.2005.00432.x

Monnet, F. P., and Maurice, T. (2006). The sigmal protein as a target for the non-genomic effects of neuro(active)steroids: molecular, physiological, and behavioral aspects. J. Pharmacol. Sci. 100, 93-118. doi: 10.1254/jphs.CR00 50032

Morin-Surun, M. P., Collin, T., Denavit-Saubié, M., Baulieu, E. E., and Monnet, F. P. (1999). Intracellular sigmal receptor modulates phospholipase $C$ and protein kinase C activities in the brainstem. Proc. Natl. Acad. Sci. U.S.A. 96, 8196-8199. doi: $10.1073 /$ pnas. 96.14 .8196
Muñoz-Gutierrez, C., Adasme-Carreño, F., Fuentes, E., Palomo, I., and Caballero, J. (2016). Computational study of the binding orientation and affinity of PPAR $\gamma$ agonists: inclusion of ligand-induced fit by cross-docking. RSC Adv. 6, 64756-64768. doi: 10.1039/C6RA12084A

Muñoz-Gutiérrez, C., Cáceres-Rojas, D., Adasme-Carreño, F., Palomo, I., Fuentes, E., and Caballero, J. (2017). Docking and quantitative structure-activity relationship of bi-cyclic heteroaromatic pyridazinone and pyrazolone derivatives as phosphodiesterase 3A (PDE3A) inhibitors. PLoS ONE 12:e0189213. doi: 10.1371/journal.pone.0189213

Navarro-Retamal, C., and Caballero, J. (2016). Flavonoids as CDK1 inhibitors: insights in their binding orientations and structure-activity relationship. PLoS ONE 11:e0161111. doi: 10.1371/journal.pone.0161111

Navarro-Retamal, C., and Caballero, J. (2018). "Molecular modeling of tau ProlineDirected Protein Kinase (PDPK) inhibitors," in Computational Modeling of Drugs Against Alzheimer's Disease Neuromethods, ed K. Roy (New York, NY: Humana Press), 305-345. doi: 10.1007/978-1-4939-7404-7_13

Osguthorpe, D. J., Sherman, W., and Hagler, A. T. (2012). Generation of receptor structural ensembles for virtual screening using binding site shape analysis and clustering. Chem. Biol. Drug Des. 80, 182-193. doi: 10.1111/j.1747-0285.2012.01396.x

Pastor, M., Cruciani, G., and Clementi, S. (1997). Smart region definition: a new way to improve the predictive ability and interpretability of three-dimensional quantitative structure-activity relationships. J. Med. Chem. 40, 1455-1464. doi: $10.1021 / \mathrm{jm} 9608016$

Peviani, M., Salvaneschi, E., Bontempi, L., Petese, A., Manzo, A., Rossi, D., et al. (2014). Neuroprotective effects of the Sigma-1 receptor (S1R) agonist PRE084, in a mouse model of motor neuron disease not linked to SOD1 mutation. Neurobiol. Dis. 62, 218-232. doi: 10.1016/j.nbd.2013.10.010

Prezzavento, O., Campisi, A., Ronsisvalle, S., Li Volti, G., Marrazzo, A., Bramanti, V., et al. (2007). Novel sigma receptor ligands: synthesis and biological profile. J. Med. Chem. 50, 951-961. doi: 10.1021/jm0611197

Quesada-Romero, L., and Caballero, J. (2014). Docking and quantitative structureactivity relationship of oxadiazole derivates as inhibitors of GSK3beta. Mol. Divers. 18, 149-159. doi: 10.1007/s11030-013-9483-5

Quesada-Romero, L., Mena-Ulecia, K., Tiznado, W., and Caballero, J. (2014). Insights into the interactions between maleimide derivates and GSK3 $\beta$ combining molecular docking and QSAR. PLOS ONE 9:e102212. doi: 10.1371/journal.pone.0102212

Quesada-Romero, L., Mena-Ulecia, K., Zuñiga, M., De-la-Torre, P., Rossi, D., Tiznado, W., et al. (2015). Optimal graph-based and simplified molecular input line entry System-based descriptors for quantitative structureactivity relationship analysis of arylalkylaminoalcohols, arylalkenylamines, and arylalkylamines as $\sigma 1$ receptor ligands. J. Chemom. 29, 13-20. doi: $10.1002 / \mathrm{cem} .2650$

Ramírez, D., and Caballero, J. (2018). Is it reliable to take the molecular docking top scoring position as the best solution without considering available structural data? Molecules 23:1038. doi: 10.3390/molecules23051038

Rossi, D., Marra, A., Picconi, P., Serra, M., Catenacci, L., Sorrenti, M., et al. (2013a). Identification of RC-33 as a potent and selective $\sigma 1$ receptor agonist potentiating NGF-induced neurite outgrowth in PC12 cells. Part 2: g-scale synthesis, physicochemical characterization and in vitro metabolic stability. Bioorg. Med. Chem. 21, 2577-2586. doi: 10.1016/j.bmc.2013.02.029

Rossi, D., Marra, A., Rui, M., Laurini, E., Fermeglia, M., Pricl, S., et al. (2015). A step forward in the sigma enigma: a role for chirality in the sigmal receptor-ligand interaction? Med. Chem. Commun. 6, 138-146. doi: 10.1039/C4MD00349G

Rossi, D., Pedrali, A., Gaggeri, R., Marra, A., Pignataro, L., Laurini, E., et al. (2013b). Chemical, pharmacological, and in vitro metabolic stability studies on enantiomerically pure RC-33 compounds: promising neuroprotective agents acting as $\sigma 1$ receptor agonists. ChemMedChem 8, 1514-1527. doi: $10.1002 / \mathrm{cmdc} .201300218$

Rossi, D., Pedrali, A., Urbano, M., Gaggeri, R., Serra, M., Fernández, L., et al. (2011). Identification of a potent and selective $\sigma 1$ receptor agonist potentiating NGF-induced neurite outgrowth in PC12 cells. Bioorg. Med. Chem. 19, 6210-6224. doi: 10.1016/j.bmc.2011.09.016

Rossi, D., Rui, M., Di Giacomo, M., Schepmann, D., Wünsch, B., Monteleone, S., et al. (2017). Gaining in pan-affinity towards sigma 1 and sigma 2 receptors. SAR studies on arylalkylamines. Bioorg. Med. Chem. 25, 11-19. doi: 10.1016/j.bmc.2016.10.005 
Rossi, D., Urbano, M., Pedrali, A., Serra, M., Zampieri, D., Mamolo, M. G., et al. (2010). Design, synthesis and SAR analysis of novel selective sigmal ligands (Part 2). Bioorg. Med. Chem. 18, 1204-1212. doi: 10.1016/j.bmc.2009.12.039

Rui, M., Rossi, D., Marra, A., Paolillo, M., Schinelli, S., Curti, D., et al. (2016). Synthesis and biological evaluation of new aryl-alkyl(alkenyl)4-benzylpiperidines, novel Sigma Receptor (SR) modulators, as potential anticancer-agents. Eur. J. Med. Chem. 124, 649-665. doi: 10.1016/j.ejmech.2016.08.067

Schmidt, H. R., Betz, R. M., Dror, R. O., and Kruse, A. C. (2018). Structural basis for $\sigma 1$ receptor ligand recognition. Nat. Struct. Mol. Biol. 25, 981-987. doi: 10.1038/s41594-018-0137-2

Schmidt, H. R., Zheng, S., Gurpinar, E., Koehl, A., Manglik, A., and Kruse, A. C. (2016). Crystal structure of the human $\sigma 1$ receptor. Nature 532, 527-530. doi: 10.1038/nature17391

Shelley, J. C., Cholleti, A., Frye, L. L., Greenwood, J. R., Timlin, M. R., and Uchimaya, M. (2007). Epik: a software program for $\mathrm{pK}(\mathrm{a})$ prediction and protonation state generation for drug-like molecules. J. Comput. Aided Mol. Des. 21, 681-691. doi: 10.1007/s10822-007-9133-z

Singh, J., Deng, Z., Narale, G., and Chuaqui, C. (2006). Structural interaction fingerprints: a new approach to organizing, mining, analyzing, and designing protein-small molecule complexes. Chem. Biol. Drug Des. 67, 5-12. doi: 10.1111/j.1747-0285.2005.00323.x

Tesei, A., Cortesi, M., Zamagni, A., Arienti, C., Pignatta, S., Zanoni, M., et al. (2018). Sigma receptors as endoplasmic reticulum stress "Gatekeepers" and their modulators as emerging new weapons in the fight against cancer. Front. Pharmacol. 9:711. doi: 10.3389/fphar.2018.00711

Tosco, P., and Balle, T. (2011). Open3DQSAR: a new open-source software aimed at high-throughput chemometric analysis of molecular interaction fields. J. Mol. Model. 17, 201-208. doi: 10.1007/s00894-010-0684-x

Urbano, M., Collina, S., Rossi, D., Baraglia, A. C., Alcaro, S., Artese, A., et al. (2007). Design and synthesis of a (N-AlkylaminoalkylSubstituted)arylalkenylamide drug discovery library. Lett. Drug Des. Discov. 4, 605-610. doi: 10.2174/157018007782794581

Vavers, E., Svalbe, B., Lauberte, L., Stonans, I., Misane, I., Dambrova, M., et al. (2017). The activity of selective sigma-1 receptor ligands in seizure models in vivo. Behav. Brain Res. 328, 13-18. doi: 10.1016/j.bbr.2017.04.008
Velázquez-Libera, J. L., Navarro-Retamal, C., and Caballero, J. (2018). Insights into the structural requirements of 2(S)-amino-6-boronohexanoic acid derivatives as arginase I inhibitors: 3D-QSAR, docking, and interaction fingerprint studies. Int. J. Mol. Sci. 19:2956. doi: 10.3390/ijms191 02956

Walker, J. M., Bowen, W. D., Walker, F. O., Matsumoto, R. R., De Costa, B., and Rice, K. C. (1990). Sigma receptors: biology and function. Pharmacol. Rev. 42, 355-402.

Wu, D., Wang, Q., Assary, R. S., Broadbelt, L. J., and Krilov, G. (2011). A computational approach to design and evaluate enzymatic reaction pathways: application to 1-butanol production from pyruvate. J. Chem. Inf. Model. 51, 1634-1647. doi: 10.1021/ci2000659

Yagasaki, Y., Numakawa, T., Kumamaru, E., Hayashi, T., Su, T.-P., and Kunugi, H. (2006). Chronic antidepressants potentiate via sigma-1 receptors the brainderived neurotrophic factor-induced signaling for glutamate release. J. Biol. Chem. 281, 12941-12949. doi: 10.1074/jbc.M508157200

Yous, S., Wallez, V., Belloir, M., Caignard, D. H., McCurdy, C. R., and Poupaert, J. H. (2005). Novel 2(3H)-benzothiazolones as highly potent and selective sigma-1 receptor ligands. Med. Chem. Res. 14, 158-168. doi: 10.1007/s00044-005-0131-1

Zampieri, D., Grazia Mamolo, M., Laurini, E., Zanette, C., Florio, C., Collina, S., et al. (2009). Substituted benzo[d]oxazol-2(3H)-one derivatives with preference for the sigmal binding site. Eur. J. Med. Chem. 44, 124-130. doi: 10.1016/j.ejmech.2008.03.011

Conflict of Interest Statement: The authors declare that the research was conducted in the absence of any commercial or financial relationships that could be construed as a potential conflict of interest.

Copyright (c) 2019 Velázquez-Libera, Rossino, Navarro-Retamal, Collina and Caballero. This is an open-access article distributed under the terms of the Creative Commons Attribution License (CC BY). The use, distribution or reproduction in other forums is permitted, provided the original author(s) and the copyright owner(s) are credited and that the original publication in this journal is cited, in accordance with accepted academic practice. No use, distribution or reproduction is permitted which does not comply with these terms. 